\title{
Analysis of the Gutenberg-Richter $b$-values of overlapping seismic clusters with application to Cooke 4 gold mine
}

\author{
J. von Ketelhodt, D. Ligaraba, and R.J. Durrheim \\ University of the Witwatersrand, South Africa
}

\begin{abstract}
The $b$-value of the Gutenberg-Richter frequency-magnitude relationship is an indicator of rock failure processes. Near-real-time analysis of the $b$-value has the potential to mitigate the risk posed by rockbursts, for example, by adjusting the geometry, sequence and rate of mining; or evaluating the re-entry time following a large seismic event. There are two main approaches to selecting a data set for $\boldsymbol{b}$-value analysis: (i) select seismic events that fall within polygons or polyhedra associated with particular working places or seismic sources (e.g. a development end, stope or fault); or (ii) select seismic events that occur in the vicinity of each node of a 2D or 3D mesh that covers the entire region of interest.
\end{abstract}

Challenges include the inevitable trade-off between statistical stability and space-time resolution, and overlaps of clusters of seismic events that arise from different sources. We wrote a Matlab code "Bplot" to conduct numerical simulations to investigate strategies to improve the resolution and reliability of $b$-value analysis. Bplot was also used to analyse seismicity during the extraction of the shaft pillar at Cooke 4 gold mine. Approximately 450000 events, recorded from July 2011 to October 2011, were used to map spatial and temporal variations in the $b$-value. We find lower $b$-values close to the stope face. We attribute the higher $b$-value ahead of the stope to the occurrence of numerous small events caused by the fracture of intact rock by high stresses ahead of the mining front; while the relative increase in the number of larger events close to the face is considered to be the result of the growth and coalescence of these fractures.

\section{INTRODUCTION}

The statistical distribution of earthquake size and frequency follows a power law, known as the Gutenberg-Richter Relationship, Gutenberg and Richter (1944) and Ishimoto and Iida (1939)

$$
\log N=a-b M
$$

where $N$ is the number of earthquakes $\geq$ magnitude $M ; a$ is the logarithm of the number of events with $M \geq 0$ and hence an indicator of the seismic activity; and $b$ describes the slope of the generally linear relationship between $\log N$ and $M$. The $b$-value for data sets that cover large areas and extended time spans is close to 1 . However, significant variations in time and space have been observed for smaller areas and shorter times. If the $b$-value is low, then the frequency of larger earthquakes is higher than usual and vice versa.

The $b$-value has been analysed in numerous studies. Scholz (1968) analysed microseismicity in laboratory experiments and found that the $b$-value decreased with an increase in applied uniaxial or triaxial stress. Similar results were found in the field. For example, Enesco and Ito (2001) analysed the temporal changes in $b$-value before the 1995 Kobe earthquake and found an anomalous decrease of the $b$-value about 1 year before the event. 
Nuannin et al (2005a) found a similar trend prior to the 2004 Sumatra earthquake. However, these findings are not universal. Other studies suggest that the $b$-value is more or less stationary in an area, See Abercrombie and Brune (1994). Thus, a change in the $b$-value is not a reliable predictor of earthquakes.

The $b$-value distribution has also been analysed in mines. Urbancic et al (1992) found a correlation between low $b$-values and high stress, while Nuannin et al (2005b) showed that drops in the $b$-value are associated with an increased rate of larger tremors. It is common practice to assess the seismic hazard in mines by monitoring the seismicity using a local network of seismometers. See Kijko and Funk (1994) and Durrheim (2017). Hudyma and Potvin (2004) developed a seismic hazard scale specifically for underground hard rock mines, and the $b$-value analysis can play an important role in this seismic hazard assessment. More recently, a Japanese-South African collaborative research project (Ogasawara et al, 2014), carried out high-sensitivity monitoring of seismicity produced during the extraction of a shaft pillar in a deep Witwatersrand gold mine, and, among many others topics, studied the $b$-value Naoi et al (2014). This will be discussed in more detail in the Results section of this paper.

\section{METHODS}

\section{Determining the $b$-value}

The value of $b$ in equation [1] may be determined by linear regression, (See Gutenberg and Richter (1944); Abercrombie and Brune (1994) and Nuannin et al (2005a)), or by the maximum likelihood method

$$
b=\log _{10} \mathrm{e} /\left(M_{a v}-M_{\min }\right)
$$

where $M_{a v}$ is the average magnitude and $M_{\min }$ is the smallest magnitude event of the catalogue. This method was first suggested by Utsu (1965). Aki (1965) added confidence intervals to the $b$-value. Bender (1983) extended the equation to account for the limited accuracy of magnitude estimates (usually \pm 0.1 ), which can introduce rounding errors in the $b$-value computation.

$$
b=\log _{10} \text { e } /\left(M_{a v}-\left(M_{m i n}-b i n / 2\right)\right)
$$

where bin is the width of the magnitude bins used to sort the earthquake catalogue. The maximum likelihood method is more accurate than a linear regression, as errors in the magnitude calculation are considered equally, irrespective of the seismic event's magnitude. This is not the case for the linear regression method, because errors of the large magnitude events contribute more than errors prevalent in small magnitude events.

\section{Determining the magnitude of completeness $\left(M_{c}\right)$}

The magnitude of completeness $\left(M_{c}\right)$ is the smallest magnitude event for which all of the events in a spatially and temporally limited volume are recorded. Below $M_{c}$, a fraction of events are not detected by the installed seismometers. The missed events could be too small to be recorded or located accurately by the particular seismic monitoring system, or they could occur in an aftershock sequence and be hidden within the coda of larger events, see Woessner and Wiemer (2005). It is also conceivable that the automatic picking algorithm used by a particular seismic system failed to detect such a small event.

An earthquake catalogue is heterogeneous and highly complex. Habermann and Creamer (1994) show that most of the observed changes in catalogue seismicity are related to a change in the reporting system (i.e., mine seismometer network configuration, failure of seismometer stations), while the implementation of new software algorithms can lead to different magnitudes of completeness, which in turn affects the seismicity rates and the $b$-value. Oftentimes, such man-made changes can be identified by careful examination of the seismicity rates, Habermann (1987) and Morkel and Wesseloo (2017). 
There are several different methods to determine $M_{c}$. The first category assumes self-similarity, which implies a power law distribution of the events, as suggested by Gutenberg and Richter. The second category uses the difference in detection thresholds at different times. For example, on a mine where there are different levels of activity at different times of the daily or weekly mining cycle, the ratio of earthquake frequencies may be used to determine $M_{c}$, Rydelek and Sacks (1989). Comparing different time windows (such as blasting time, night and day shifts and weekends) is somewhat inconvenient, as the events would first have to be sorted by time of day before $M_{c}$ could be determined. This would be computationally intensive, if performed for many grid points. Thus, the maximum curvature method, which computes the first derivative of the frequency-magnitude curve, was used. It is the simplest and fastest $M_{c}$ calculation method, Wiener and Wyss (2000). It has been shown that the peak in the first derivative matches the magnitude bin with the highest number of non-cumulative events but often underestimates $M_{c}$, Woessner and Wiemer (2005). To counteract this underestimation, Woessner and Wiemer (2005), propose adding a constant value to the $M_{c}$ and spot check the results. We added a value of 0.1 to the $M_{c}$ determined by the maximum likelihood method.

\section{Implementation of MATLAB code Bplot}

The MATLAB code Bplot was written by Von Ketelhodt (2014) and further developed by Ligaraba (2018). The major computational steps are:

1. Creation of a 3D grid to cover the data space. In the examples presented here, we have used $20 \times 20 \times 20=8000$ nodes.

2. Calculation of the $b$-value at each node. A function is called to determine the number of events that are within a given radius of the node, termed the search radius. If the number of events within the search radius is bigger than the chosen minimum number of events, then $M_{c}$ is determined and the $b$-value is calculated using the maximum likelihood method.

Challenges include the inevitable trade-offs between statistical stability and space-time resolution, and overlapping clusters of seismic events arising from different sources (See Figure 1).

The search radius determines the distance from each grid point for which events are included in the $b$ value calculation. The benefit of a decrease in the search radius is an increase in the spatial accuracy and resolution of the $b$-value analysis, while the benefit of an increase in the search radius is an increase in the number of events that can be used to calculate the $b$-value, and hence the statistical robustness. Secondly, the user can choose the minimum number of events that have to occur within the search radius of every grid point for the $b$-value calculation to be valid. Woessner and Wiemer (2005) recommend that the sample size should be more than 200 events. Wesseloo (2014) has shown that if too few events occur within a distance of a grid point, then the $b$-value calculation is no longer robust. Other important factors are the spatial and statistical distribution of events within the search radius (Wesseloo, 2014). For example, if all events occur on one side of the search radius, or if the events are not dense enough around the grid point, then the $b$-value calculation might not be representative of that grid point (Figure 1). We conducted a series of numerical simulations to investigate these issues.

This implementation of Bplot is simplistic. We plan to develop the code to dynamically vary the node spacing, search radius and time window so as to optimize spatial and temporal resolution, statistical stability, and diagnostic ability. To do this we need to take the following factors into account: the accuracy in hypocenter location, which depends on the configuration of the sensor array; the activity rate, which is roughly proportional to the rate of mining, but also depends on the time of the blast, failure mechanisms, mining method and regional support systems; and variations in source parameters that affect hazard other than magnitude, such as moment, energy and stress drop. 


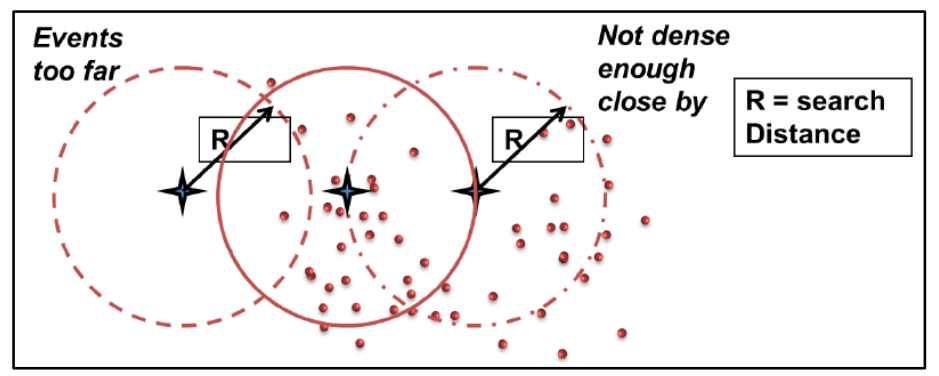

Figure 1. Events (dots) within a search radius of a grid point (crosses). The left grid point has too few events within the search radius, the middle grid point has adequate number of events and the right grid point has an adequate number of grid points in the search radius, but the density of the events is not high enough close to the grid point, after Wesseloo (2014)

\section{RESULTS}

\section{Numerical simulations}

Bplot was used to conduct numerical simulations to investigate strategies that may be used to improve the resolution and reliability of $b$-value analysis. We created overlapping ellipsoidal clusters of seismic events of increasing complexity (See Figure 2). Various sources of mining seismicity can be simulated by changing the length of the ellipsoid axes. For example, a 3D spherical cluster might represent instability in a pillar; a 2D disc the instability on a fault or dyke induced by the approach of a tunnel or stope; and a 1D pencil the instability ahead of the face of a deep, narrow tabular stope. The $b$-value may be related to the stress regime or dimensionality of the source, See Legge and Spottiswoode (1987); Scholz (20150 and Wu et al (2018). For example, a 1-D source may yield a $b$-value of 0.5 , while a 3D source may yield a $b$-value of 1.5 .

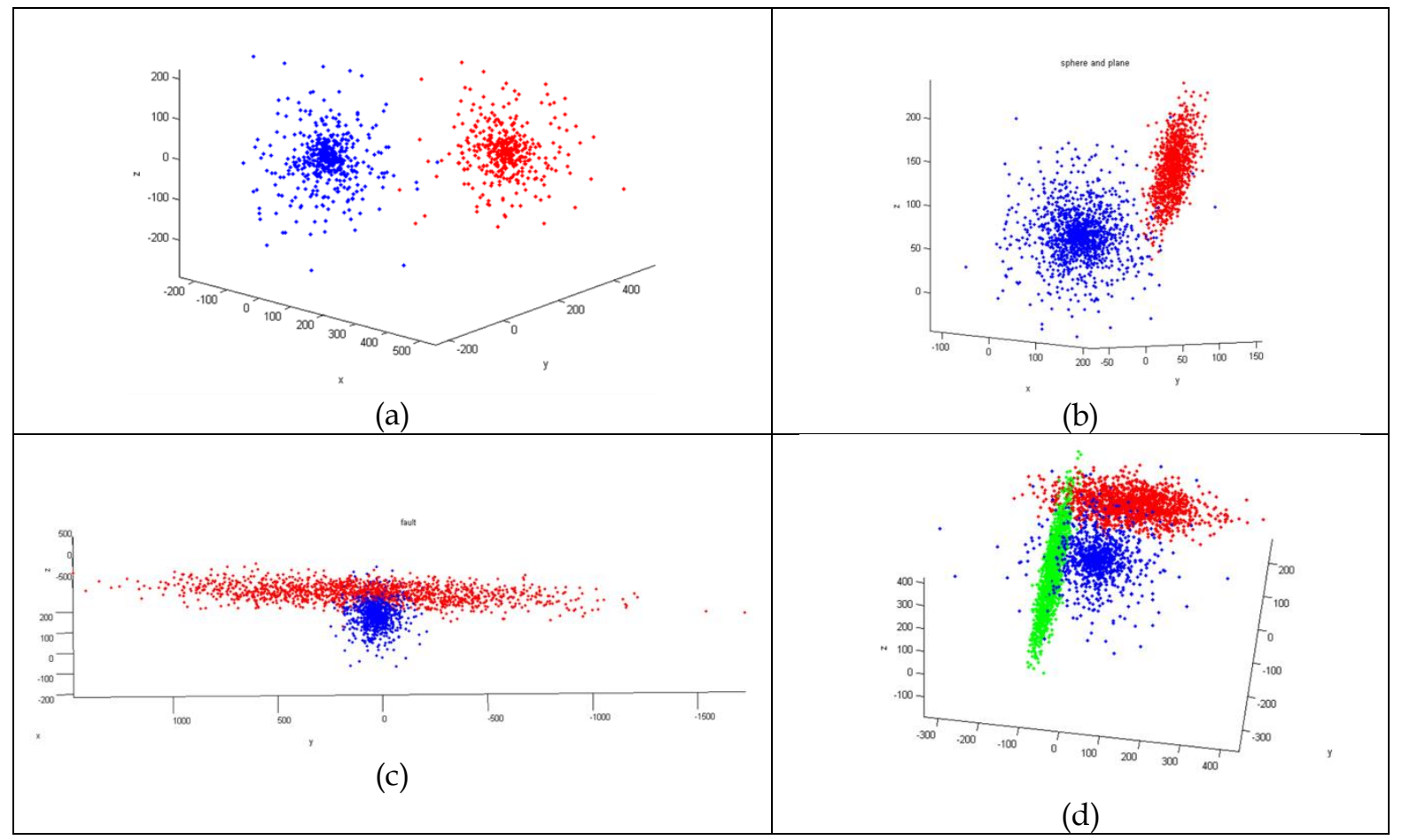

Figure 2. Generation of synthetic clusters with different shapes and $a$ - and b-values. The focus of each event is plotted. Colours are used to distinguish events belonging to different clusters. (a) Two separated spherical clusters, the blue and red clusters have b-values of 0.5 and 1, respectively; (b) and (c) overlapping spherical and 
disc clusters; (d) overlapping spherical, disc and pencil clusters

Each synthetic cluster is characterised by a unique set of parameters: the Gutenberg-Richter $a$ - and $b$ values, and the spatial and temporal distribution of the seismicity. For example, we can model the seismicity following a large event by distributing the aftershocks within a spherical cluster that is centered on the main shock but with the aftershock hypocenter density decreasing according to a Gaussian function and the rate decreasing according to the Modified Omori law. Unsurprisingly, we found that the $b$-value determined at a particular node is determined by the population of events within its search radius, and that some nodes will sample data events from more than one cluster, yielding a mixed $b$-value (See Figure 3). An obvious first step is to determine the 'goodness of fit' of the slope of the $b$-value line, and reject values with large uncertainties. The next phase of the project will be to develop machine-learning tools that will attempt to differentiate the clusters and determine their characteristics.

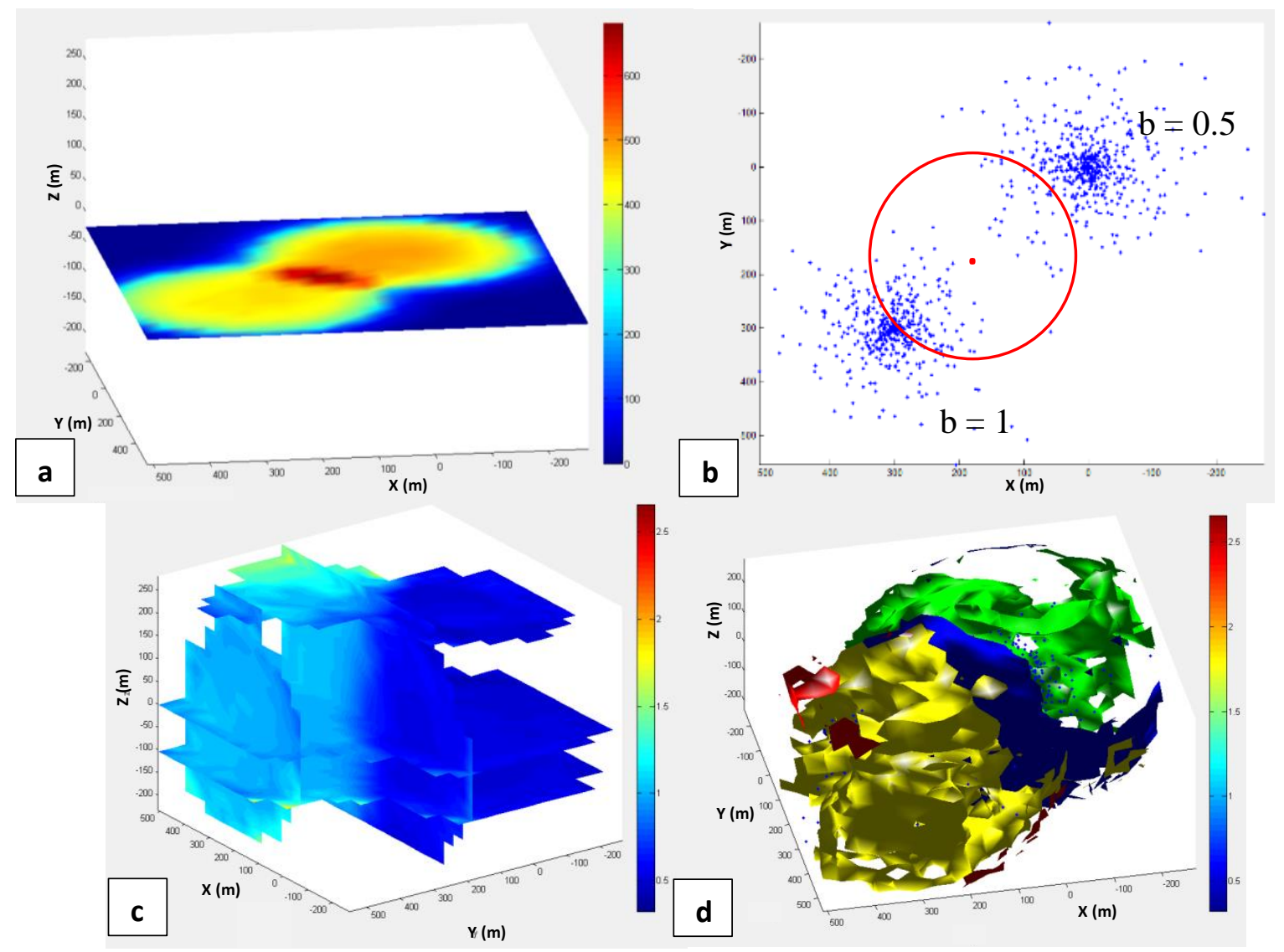




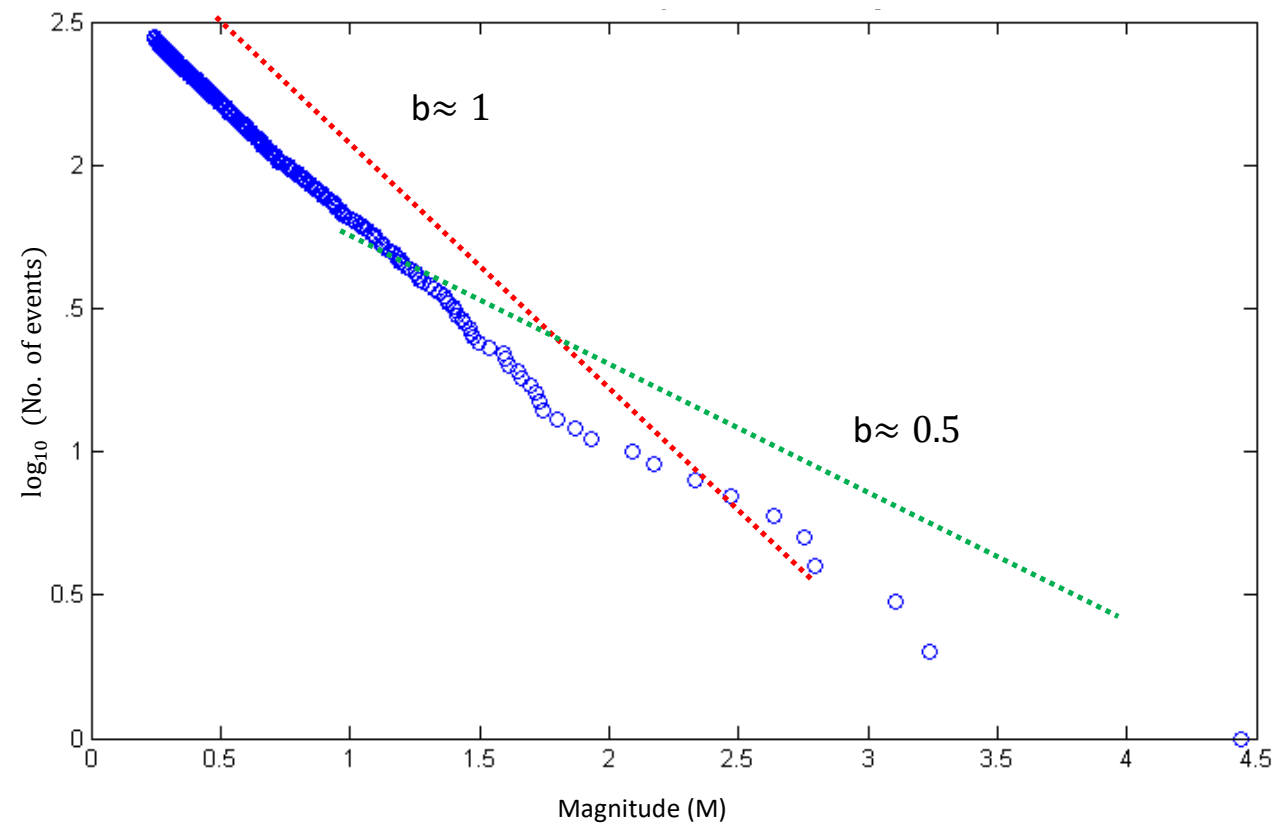

Figure 3. b-value analysis (a) number of events within a search radius of every grid point; (b) events of the two separated spherical clusters; (c) spatial distribution of b-values; (d) isosurfaces of b-value with blue, green and red indicating $b=0.5,0.7,1$ and 1.5, respectively; (e) Gutenberg-Richter plot for node shown in (b) that samples events from spherical clusters with differing b-values

\section{Case study: Cooke 4 gold mine}

Seismicity was recorded during the mining of the $400 \mathrm{~m}$ diameter shaft pillar of Cooke 4 gold mine as part of the Japanese/ South African collaborative project: Observational studies in South African mines to mitigate seismic risks, Ogasawara (2014) to identify and map seismic sources and monitor localized damage accumulation and evolution. An array comprising six accelerometers and 28 acoustic emission (AE) sensors were installed $1 \mathrm{~km}$ below surface, spanning a volume approximately $100 \mathrm{~m}$ in diameter. Naoi et al (2014) provide a detailed account of recording, processing and interpretation procedures. The average spacing of the sensors, grouted in boreholes, was about $15 \mathrm{~m}$. The sampling rate on all channels was $500 \mathrm{kHz}$. Events were located with decimeter accuracy using double-difference and 'collapsing' methods. Many events with a useable signal-to-noise ratio up to $50 \mathrm{kHz}$ were recorded and AEs with magnitudes as small as $\mathrm{M}_{\mathrm{W}}-5.3$ were detected. A catalogue of $\sim 1.02$ million seismic events collected from 10 July 2011 to 25 March 2012 was used to study the frequency-magnitude distribution of acoustic emissions, Naoi et al (2014), the formation of damage structures ahead of the mining front, Moriya et al (2015), the unexpectedly frequent occurrence of very small repeating earthquakes, Naoi et al (2016), quasi-static growth of a slip-patch on a pre-existing fault Naoi et al (2015) and the properties of the rupture zone revealed by repeating events, Yamaguchi et al (2018). Naoi et al (2014) found that a Gutenberg-Richter law with $\mathrm{b} \approx 1.2$ was valid between $\mathrm{M}_{\mathrm{w}}-3.7$ and 0 for acoustic emissions around the mining front, where $\mathrm{M}_{\mathrm{w}}$ is the moment magnitude.

We used a subset of approximately 450000 events recorded from July 2011 to October 2011 (See Figure 4 ) to test Bplot and map the spatial and temporal variation of $b$-values in detail. The search radius was kept as small as possible ( $15 \mathrm{~m}$ for the entire catalogue and $7 \mathrm{~m}$ for sub-sets) without compromising the accuracy of a calculated $b$-value. The minimum number of events was specified as 500 to minimize errors in the $b$-value calculation; if a larger value had been used, the number of valid $b$-value calculations would have been smaller and results would have been less conclusive. 


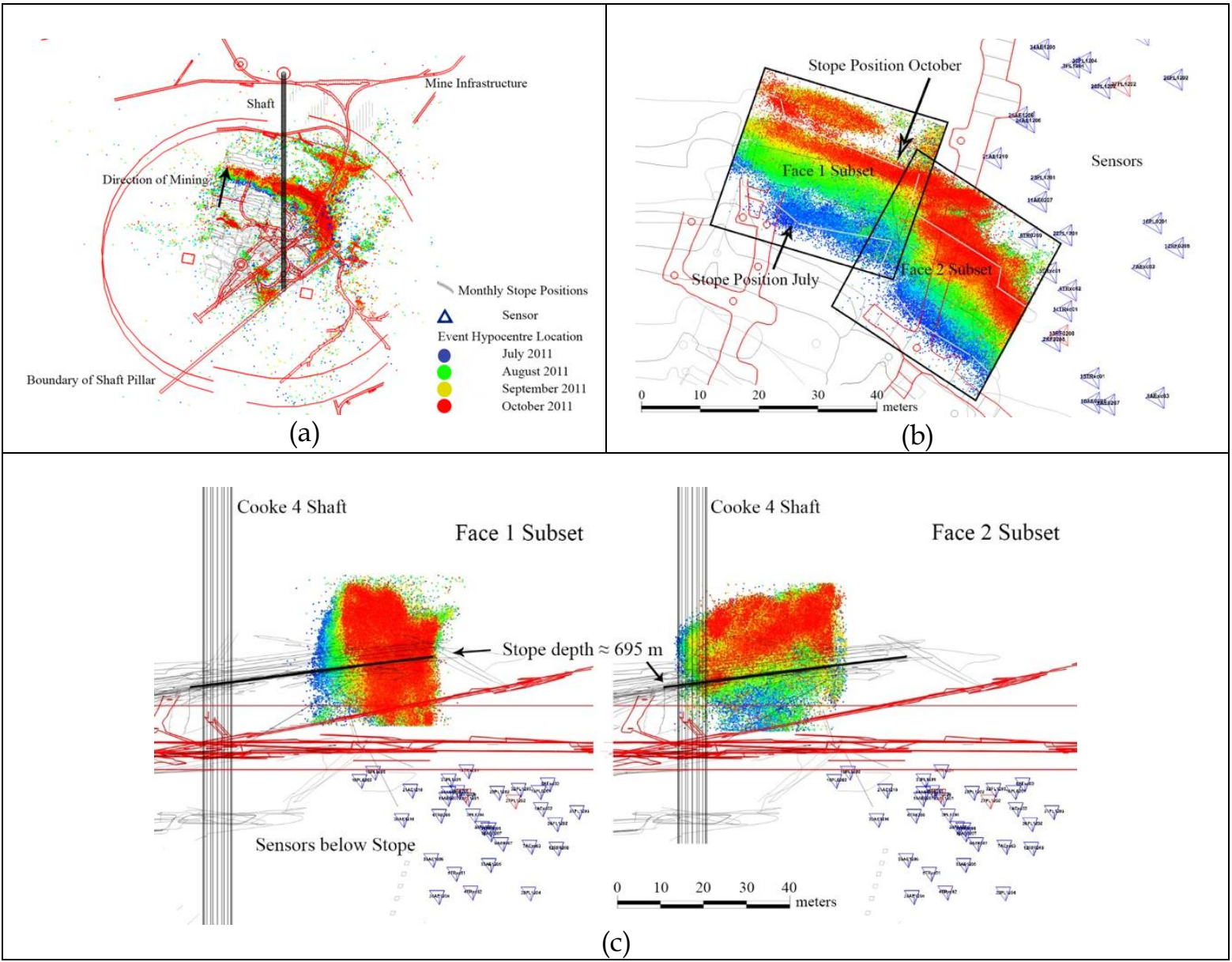

Figure 4. (a) Oblique view of mining of the Cooke 4 shaft pillar and hypocenters of seismic events that occurred between 1 July to 31 October 2011; (b) plan view of the seismicity subsets (Face 1 and Face 2) viewed from above; (c) section view of the seismicity subsets (Face 1 and Face 2)

The statistical analysis of the events in the Cooke 4 shaft pillar revealed changes in the frequencymagnitude distribution that correlate with the position of the grid node relative to the mining stope (See Figure 5). The spatial $b$-value calculation showed slightly different results for the two data subsets. In the case of Face 1, the $b$-value was observed to increase near the October 2011 face position, while the $b$ value was more or less constant over the remainder of the mining area. Relatively stable $b$-values were observed in the Face 2 dataset. The region of higher $b$-values is attributed to large numbers of very small earthquakes occurring in intact rock triggered by the stress peak ahead of the mining stope. The remainder of the data set has a lower $b$-value because of an increase in the number of larger events owing to the growth and coalescence of the fractures. 


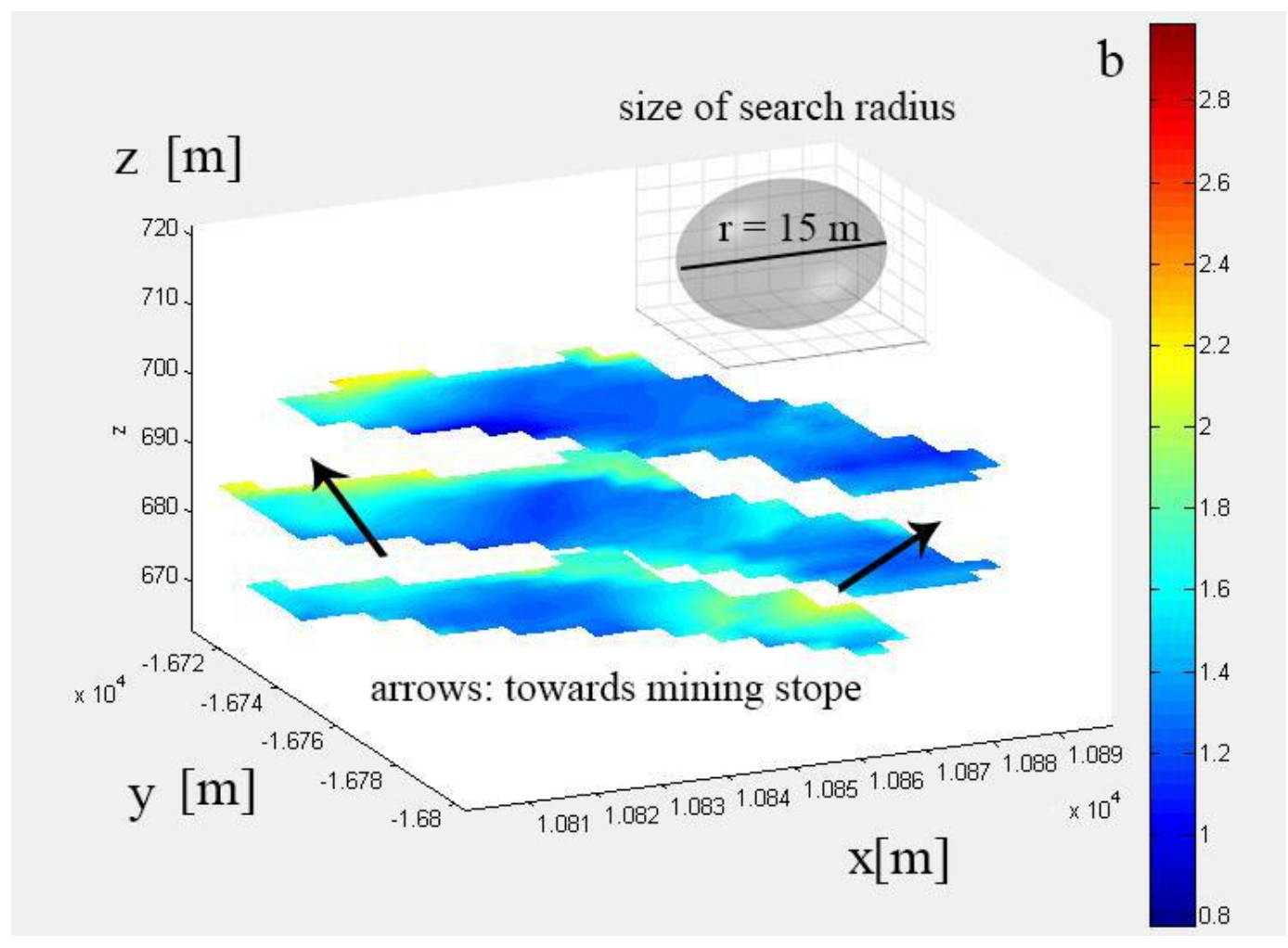

Figure 5. Spatial distribution of b-values on three depth slices in part of the Cooke 4 shaft pillar. The view is in the direction of mining. The stope is at a depth of approximately 695. The stoped-out pillar is in the foreground and the outer edge of the shaft pillar in the distance. The b-value is lower close to the face

\section{DISCUSSION AND CONCLUSIONS}

Near-real-time analysis of variations in seismicity parameters could potentially lead to advances in the detection of instabilities in the rock mass. However, many questions remain: Which parameters are diagnostic? What changes are significant? Here we report on efforts at the University of the Witwatersrand to investigate these phenomena and determine which factors are epistemic (i.e. due to a lack of knowledge and/or data and could be overcome by better monitoring and analysis) and which are aleatoric (i.e., the natural randomness of the process).

The Bplot Matlab code has been developed by BSc Honours (Geophysics) students to gain a deeper understanding of the statistical analysis of mining-induced seismicity, in particular temporal and spatial variations of the $b$-value. We show that $b$-value estimates may be contaminated by overlapping clusters arising from different sources. We have tested the code on a high-quality data set collected in the shaft pillar of Cooke 4 mine comprising over 450000 events $-3.7 \leq \mathrm{M}_{\mathrm{w}} \leq 0$ that are located with decimetre accuracy. In the next phase of the project we plan to improve the reliability and resolution of our analyses using machine-learning techniques.

\section{ACKNOWLEDGEMENTS}

We thank Gold One International Ltd., operator of the Cooke 4 shaft, and also personnel at the mine and at the Institute of Mine Seismology for facilitating our project. This project was funded by grantsin-aid from the Ministry of Education, Culture, Sports, Science and Technology (MEXT) of Japan (21224012, 21246134). It was also funded by JST/JICA, SATREPS, and the MEXT's Observation and Research Program for Prediction of Earthquakes and Volcanic Eruptions. 


\section{REFERENCES}

Abercrombie, R. E. and Brune, J. N. (1994). Evidence for a constant b-value above magnitude 0 in the southern San Andreas, San Jacinto and San Miguel fault zones, and at the Long Valley caldera, California. Geophysical Research Letters, 21, 1647-1650.

Aki, K. (1965). Maximum Likelihood Estimates of $\mathrm{b}$ in the formula $\log \mathrm{N}=\mathrm{a}-\mathrm{bM}$ and its confidence limits. Bulletin of the Earthquake Research Institute of the University of Tokyo, 237-239.

Bender, B. (1983). Maximum likelihood estimation of b-values for magnitude grouped data. Bulletin of the Seismological Society of America, 73, 831-851.

Durrheim, R. J. (2017). Microseismic monitoring technologies for deep mining, In Rock Mechanics and Engineering, Vol. 4: Excavation, Support and Monitoring, Xia-Ting Feng (editor), CRC Press/Balkema, pp. 339-364.

Enesco, B. and Ito, K. (2001). Some premonitory phenomena of the 1995 Hyogo-Ken Nanbu (Kobe) earthquake: seismicity, b-value and fractal dimension. Tectonophysics, 338, 297-314.

Gutenberg, B. and Richter, C. F. (1944). Frequency of earthquakes in California. Bulletin of the Seismological Society of America, 34, 185-188.

Habermann, R. E. (1987). Man-made changes of seismicity rates. Bulletin of the Seismological Society of America, 77, 141-159.

Habermann, R. E., and Creamer, F. (1994). Catalog errors and the M8 earthquake prediction algorithm. Bulletin of the Seismological Society of America, 84, 1551-1559.

Hudyma, M. and Potvin, Y. (2004). Seismic Hazard in Western Australian Mines. Journal of the South African Institute of Mining and Metallurgy, 104, 265-276.

Ishimoto, M. and Iida, K. (1939). Observations sur les seismes enregistres par le microsismographe construit dernierement (in Japanese with French abstract). Bulletin of the Earthquake Research Institute, University of Tokyo, 443-478.

Kijko, A. and Funk, C. W. (1994). The assessment of seismic hazards in mines. Journal of the South African Institute of Mining and Metallurgy, 94, 179-185.

Legge, N. B. and Spottiswoode, S. M. (1987). Fracturing and microseismicity ahead of a deep gold mine stope in the pre-remnant and remnant stages of mining. In 6th International Conference on Rock Mechanics, A A Balkema, Montreal, Canada, 1071-1077.

Ligaraba, D. (2018). Space-time analysis of mine seismic data, BSc (Honours) dissertation (unpublished), University of the Witwatersrand.

Mathworks Inc. (2012). Matlab Help Documentation R2012b. Mathworks Inc.

Moriya, H., Naoi, M., Nakatani, M., Van Aswegen, G., Murakami, O., Kgarume, T., Ward, A. K., Durrheim, R., Philipp, J., Yabe, Y., Kawakata, H. and Ogasawara, H. (2015). Delineation of large localized damage structures forming ahead of an active mining front in the Cooke 4 Mine, South Africa, by using advanced acoustic emission mapping techniques, International Journal of Rock Mechanics \& Mining Sciences, 79, 157-165.

Morkel, G. and Wesseloo, J. (2017). A technique to determine systematic shifts in microseismic databases, Proceedings of the 8th International Conference on Deep and High Stress Mining, J. Wesseloo (ed.), Australian Centre for Geomechanics, pp. 105-116. 
Naoi, M., Nakatani, M., Philipp, J., Horiuchi, S., Otsuki, K., Kgarume, T., Morema, G., Khambule, S., Masakale, T., Miyakawa, K., Watanabe, A., Moriya, H., Murakami, O., Yabe, Y., Kawakata, H., Yoshimitsu, N., Ward, T., Durrheim, R. and Ogasawara, H. (2014). Frequency-magnitude distribution of $-3.7<\mathrm{M}_{\mathrm{W}}<1.3$ mining-induced earthquakes and b-value invariance with post-blast time, Pure and Applied Geophysics, 171, 2665-2684.

Naoi M., Nakatani M., Horiuchi S., Yabe Y., Philipp J., Kgarume T., Morema G., Khambule S., Masakale T., Ribeiro L., Miyakawa K., Watanabe A., Otsuki K., Moriya H., Murakami O., Kawakata H., Yoshimitsu N., Ward T.A., Durrheim R., Ogasawara H. (2014). Frequency-magnitude distribution of $-3.7 \leq \mathrm{M}_{\mathrm{W}} \leq 1$ mining-induced earthquakes around a mining front and $\mathrm{b}$ value invariance with post-blast time. Pure and Applied Geophysics, 171, 2665-2684.

Naoi, M., Nakatani, M., Kgarume, T., Morema, G., Khambule, S., Masakale, T., Ribeiro, L., Philipp, J., Horiuchi, S., Otsuki, K., Miyakawa, K., Watanabe, A., Moriya, H., Murakami, O., Yabe, Y., Kawakata, H., Yoshimitsu, N., Ward, A., Durrheim, R. and Ogasawara, H. (2015). Quasi-static slip patch growth to $20 \mathrm{~m}$ inferred from acoustic emissions in a South African gold mine. Journal of Geophysical Research Solid Earth, 120, 1692-1707.

Naoi, M., Nakatani, M., Otsuki, K., Yabe, Y., Kgarume, T., Murakami, O., Masakale, T., Ribeiro, L., Ward, A., Moriya, H., Kawakata, H., Durrheim, R. and Ogasawara, H. (2015). Steady activity of microfractures on geological faults loaded by mining stress. Tectonophysics, 649, 100-114.

Naoi, M., Nakatani, M., Igarashi, T., Otsuki, K., Yabe, Y., Kgarume, T., Murakami, O., Masakale, T., Ribeiro, L., Ward, A., Moriya, H., Kawakata, H., Nakao, S., Durrheim, R. and Ogasawara, H. (2015). Unexpectedly frequent occurrence of very small repeating earthquakes with $-5.1 \leq \mathrm{M}_{W} \leq-$ 3.6 in a gold mine in South Africa. Journal of Geophysical Research, 120, 8478-8493.

Nuannin, P., Kulhanek, O. and Persson, L. (2005). Spatial and temporal b value anomalies preceding the devastating off coast of NW Sumatra earthquake of December 26, 2004. Geophysical Research Letters, 32, L11307.

Nuannin, P., Kulhanek, O., Persson, L. and Askemur, T. (2005). Inverse correlation between induced seismicity and b-value, observed in the Zingruvan Mine, Sweden. Acta Geodynamica et Geomaterialia, 2, 5-13.

Ogasawara, H., Nakatani, M., Durrheim, R .J., Naoi, M., Yabe, Y., Moriya, H., Hofmann, G.F., Stander, C., Roberts, D. P., De Bruin, P., Oelofse, J., Kato, H., Cichowicz, A., Birch, D., Ngobeni, D., Milev, A., Kgarume, T., Satoh, T., Horiuchi, S., Kawakata, H., Murakami, O., Yoshimitsu, N., Ward, A. K., Wienand, J., Lenegan, P., Yilmaz, H., Mngadi, S., Piper, P. S., Clements, T. N., Nakao, S., Okubo, M., Ishii, H. and Visser, A. V. (2014). Observational studies of the rock mass response to mining in highly stressed gold mines in South Africa, Proceedings of 7th International Congress on Deep and High Stress Mining, Sudbury, Canada, 16-18 September 2014, M. Hudyma and Y. Potvin (eds), Australian Centre for Geomechanics, pp. 123-137.

Rydelek, P. A. and Sacks, I. S. (1989). Testing the completeness of earthquake catalogues and the hypothesis of self-similarity. Nature, 337, 251-253.

Scholz, C. H. (1968). The frequency-magnitude relation of microfracturing in rock and its relation to earthquakes, Bulletin of the Seismological Society of America, 58, 399-415.

Scholz, C. H. (2015). On the stress dependence of the earthquake b value, Geophysical Research Letters, 42, 1399-1402.

Urbancic, T. I., Trifu, C.-I., Long, J. M. and Young, R. P. (1992). Space-time correlations of b values with stress release. Pure and Applied Geophysics, 139, 449-462.

Utsu, T. (1965). A method for determining the value of $b$ in the formula $\log (n)=a-b M$ Showing the magnitude frequency relation for earthquakes. Geophysical Bulletin of Hokkaido University (in 
Japanese), 99-103.

Von Ketelhodt, J. K. F. (2014). Seismicity in the Cooke 4 Shaft Gold Mine: Analysing spatial and temporal bvalue variations, BSc (Honours) dissertation (unpublished), University of the Witwatersrand.

Wesseloo, J. (2014). Grid Based Analysis of Seismic Data. Proceedings of the 6th South African Rock Engineering Symposium. Misty Hills, Muldersdrift: South African Institute of Mining and Metallurgy.

Wiemer, S. (2011). A software package to analyze seismicity: ZMap. Seismological Research Letters, 72, 373382.

Wiemer, S. and Wyss, M. (2000). Minimum magnitude of completeness in earthquake catalogs; examples from Alaska, the western United States, and Japan. Bulletin of the Seismological Society of America, 90, 859-869.

Woessner, J. and Wiemer, S. (2005). Assessing the quality of earthquake catalogues: estimating the magnitude of completeness and its uncertainty. Bulletin of the Seismological Society of America, 95, 684-698.

Wu, Y.-M., Chen, S. K., Huang, T.-C., Huang, H.-H., Chao, W.-A. and Koulakov, I. (2018). Relationship between earthquake b-values and crustal stresses in a young orogenic belt, Geophysical Research Letters, 45, 1832-1837.

Yamaguchi, J., Naoi, M., Nakatani, M., Moriya, H., Igariashi, T., Murakami, O., Yabe, Y., Durrheim, R. and Ogaswara., H. (2018). Emergence and disappearance of high-couple type repeating earthquakes on a geological fault in a gold mine in South Africa, Tectonophysics, 747/8, 318-326.

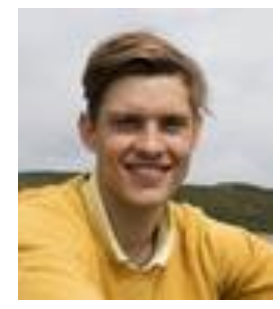

\section{Julius von Ketelhodt}

$\mathrm{PhD}$ candidate

University of the Witwatersrand

Julius von Ketelhodt has completed the requirements for a PhD at the University of the Witwatersrand. His $\mathrm{PhD}$ thesis is entitled "Seismic shear wave borehole tomography and the application of the curvelet transform to reflection seismic data". Julius was the co-winner of the Geological Society of South Africa Award for the best Honours project in the Geosciences in 2014. His Honours project was entitled "Seismicity in the Cooke 4 shaft gold mine: analysing spatial and temporal b-value variations". He is currently working in the IT sector in Germany. 


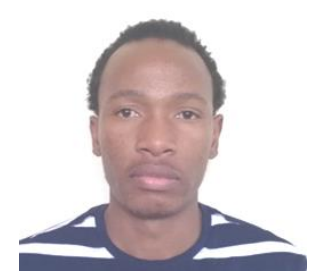

\section{Dakalo Ligaraba}

MSc candidate

University of the Witwatersrand

Dakalo Ligaraba is an MSc candidate at the University of the Witwatersrand. His research work involves the study of the strength of geological contacts in Witwatersrand Basin strata. Dakalo graduated from the University of the Witwatersrand with a BSc Hons in Geophysics in 2018. His BSc Honours project was entitled "Space-time analysis of mine seismic data".

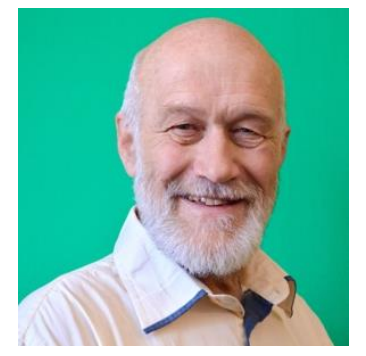

\section{Raymond Durrheim}

South African Research Chair in Exploration,

Earthquake \& Mining Seismology

University of the Witwatersrand

Raymond Durrheim holds the South African Research Chair in Exploration, Earthquake \& Mining Seismology at the University of the Witwatersrand Johannesburg. Durrheim was co-leader of the Japanese-South African collaborative project "Observational studies in South African mines to mitigate seismic risks" (2010-2015) and is currently a PI of the ICDP-DSeis project "Drilling into seismogenic zones of M2.0-M5.5 earthquakes in South African gold mines". He is also co-director of the AfricaArray research and capacity-building programme, which operates a network of 50 geophysical observatories in sub-Saharan Africa. 